\title{
Abuse of people with learning disabilities and other vulnerable adults
}

\section{Leila B. Cooke \& Valerie Sinason}

Workers in the field of learning disability drew attention to the problem of sexual abuse and learning-disabled children and adults only a decade ago (Sinason, 1986; Cooke, 1989), at the same time that British society first tolerated the knowledge that non-disabled children were being abused. Although guidelines have been produced and voluntary organisations such as the National Association for the Protection from Sexual Abuse of Adults and Children with Learning Disabilies (NAPSAC), the Association for Residential Care (ARC) and Voice UK have made vital contributions, psychiatric involvement and provision is uneven (ARC \& NAPSAC, 1993).

People with learning disability have an increased vulnerability to abuse (Brown \& Craft, 1992) because of dependence on other people for personal care; an 'imbalance of power' between the carer and the person being cared for; difficulties in communicating; lack of sexual knowledge and assertiveness; and guilt and shame at being disabled (Sinason, 1993a,b).

We consider that much of the work described in this paper can be extrapolated to other vulnerable groups, such as people who have suffered head injuries, and the elderly mentally infirm.

\section{Prevalence}

One of the first studies to be carried out in the UK involved questionnaires being sent to 34 consultant psychiatrists involved with people with learning disabilities (Cooke, 1989). The average prevalence of definite experience of abuse was found to be 4$5 \%$ of individuals. However, many consultants felt that there was likely to be a much higher hidden prevalence. There have been several further studies performed since, the largest of which was carried out in the South-East Thames Region by the Tizard Centre (Turk \& Brown, 1993; Box 1). This study concentrated only on sexual abuse but extrapolation from their results produced an expected annual incidence of 940 new cases per year in the UK. Seventy-three per cent of the victims in their study were female, and $98 \%$ of the perpetrators were male. Many of the cases reported involved one perpetrator offending against several people with learning disabilities. The perpetrator was already known to the victim in $87 \%$ of cases. Perpetrators were noted in the following categories: other people with learning disability (42\%), family members (18\%), staff/volunteers (14\%), other known adults (17\%), unknown (10\%).

\section{Presentation and diagnosis}

The presentation of abuse depends on the kind of abuse perpetrated, and the psychological impact

Box 1. Sexual abuse of people with learning disability (data from Turk \& Brown, 1993)

Predicted incidence of 940 new cases per year in the UK

$73 \%$ of victims are female

$98 \%$ of perpetrators are male

Many perpetrators abuse more than one victim

The perpetrator is known to the victim in $87 \%$ of cases

Leila B. Cooke is a consultant psychiatrist in learning disability working for the Phoenix NHS Trust, Bristol. She has had an interest in the abuse of people with learning disability for the past 10 years and is currently developing therapeutic techniques for use with such people. Valerie Sinason, is a consultant research psychotherapist at St George's Hospital Medical School, Tooting and the Tavistock and Portman Clinics (Portman Clinic, 8 Fitzjohns Avenue, London NW3 5NA). She has developed the use of psychoanalytic psychotherapy for people with learning disability, particularly for those who have been abused, and is also developing treatment approaches for perpetrators of abuse who are learning disabled. 
Box 2. Symptoms of abuse

Change in personality or behaviour

Sexually inappropriate behaviour

Withdrawal

Sleep disturbance

Loss of skills/reduced level of functioning

Loss of or reduction in speech

Self-injurious behaviour

which it had. Physical and sexual abuse and neglect may be diagnosed from physical signs and symptoms in the same way as would happen with children, but if these are not present, diagnosis can be much more difficult where the victims are nonverbal. It is therefore necessary to be aware of possible psychological manifestations of abuse, such as a change in personality or behaviour (Box 2).

The person may demonstrate an increase in sexual preoccupation, sexually inappropriate behaviour, and/or avoidant behaviour. They may be aggressive towards themself or others, be withdrawn, suffer sleep disturbances, lose previous skills and have a reduced level of functioning. Abuse must therefore always be considered as a possible differential diagnosis in someone with learning disability who presents with psychiatric symptoms.

Work with rape victims in the general population has identified certain predictors of long-term psychological disturbance (Royal College of Psychiatrists, 1996). These include prior psychological and social problems, past victimisation experiences, past psychiatric illness and lack of a supportive social network. All of these are particularly common in people with learning disability. Abuse can be a cause of post-traumatic stress disorder (PTSD)(Ryan, 1994), and can be diagnosed in subjects who are non-verbal by observing flashbacks, avoidance behaviour, increased arousal and a diminished interest in everyday activities (Box 3). Elective mutism can also occur

Box 3. Symptoms of PTSD (ICD-10)

Flashbacks

Nightmares

Emotional blunting

Detachment

Unresponsiveness

Anhedonia

Avoidance of activities or situations

Autonomic hyper-arousal in people with learning disability, sometimes in conjunction with PTSD.

\section{Investigation versus treatment}

It may sometimes appear that a choice has to be made between investigation and possibly prosecution of the perpetrator and the use of therapeutic options. Therapeutic input is just as important as investigative procedures. However, it must be acknowledged that the lack of statutory procedures and protective legislation has hampered any progress in this field (Cooke, 1990). Many cases of suspected abuse have not been investigated because of the uncertainty of professionals and the lack of an effective legal framework, although both problems are currently being addressed.

Many areas and organisations have now developed their own abuse procedures, usually based on the existing child protection procedures. To be effective, these procedures must be multiagency in origin. It is vital that all staff have adequate training in how to use them. Local adult protection committees may need to be put in place to monitor and audit the use of abuse procedures, and tackle any strategic issues that arise.

\section{Legal issues}

The use of investigative procedures would be aided enormously by the legislation currently proposed on mental incapacity. Part IX of the Law Commission's Report No. 231 concerns public law protection for vulnerable people at risk (Law Commission, 1995). A 'vulnerable person' is defined as a person of 16 or over who: (a) is or may be in need of community care services by reason of mental or other disability, age or illness and (b) is or may be unable to take care of himself or herself, or unable to protect himself or herself against significant harm or serious exploitation. It is recommended that the local authority has a clear responsibility in this area to investigate and, if necessary, take action when there is any suspicion of abuse of such a person. This legislation would give the local authority an increased range of powers, including the ability to enter and inspect premises where a vulnerable person is believed to be at risk, and to remove such a person for assessment or protection. Longer-term solutions could include amendments to Section 7(5) 
of the Mental Health Act 1983 so that only a local social services authority may be named as guardian, and to Section 8(1) to give a guardian an additional power to convey the individual to a residence specified by the guardian.

To date, there have been very few successful prosecutions against perpetrators who have abused people with learning disability. Many cases do not get to court because the Crown Prosecution Service or police considers a person with learning disability to be an unreliable witness. Even if a case is proceeded with, the court procedure is very intimidating for someone with low self-confidence and poor communication skills. A witness support scheme and the ability to use video-taped testimony, as occurs in child abuse cases, could be enormously helpful.

The issue of whether a person can give valid consent to sexual activity is particularly relevant to people with learning disability. It is currently an offence under the Sexual Offences Act 1956 for a man to have sexual intercourse with a woman who is 'defective' (defined as severe impairment of intelligence and social functioning, that is an IQ $<50$ ). This protection is extended to males who are defective in the Sexual Offences Act 1967. However, if the perpetrator can prove that he was ignorant of the person's learning disability or its severity, this can be used as a successful defence, which may be helpful when the alleged perpetrator also has learning disability. It can be very difficult to establish whether consent to intercourse was given and, if so, whether it was valid. Poor comprehension and verbal skills and low self-esteem may prevent someone with learning disability from expressing their wishes. Lack of sexual knowledge may mean they do not understand what is being done to them. Increased suggestibility can result in consent being elicited which is not valid.

\section{Treatment issues}

Provision for treatment in a new area can become nationally available only when the extent of a need is thoroughly documented, agreed upon and evokes sufficient lay and professional concern. Learning-disabled children and adults do not yet receive adequate treatment provision for emotional disturbance and /or mental illness, let alone for the emotional consequences of abuse. Indeed, when Oliver et al (1987) looked at treatment provision in their region for learning-disabled children and adults who had inflicted injuries on themselves, they found that of 596 such people only 12 were receiving any treatment. Of the 12,11 were receiving psychological treatment and one psychoanalytic therapy. Where awareness of treatment needs is also linked to figures coming from the criminal justice system, the level of reporting of cases of abuse becomes more significant. Both these factors have hindered the development of treatment facilities for the learning-disabled who are either victims or perpetrators of abuse.

\section{Treatment for victims of abuse}

Sobsey \& Varnhagen (1989) estimate that $75 \%$ of abuse cases involving learning-disabled victims are not reported to the authorities. In many such cases the environmental deficiencies that lead to lack of reporting or under-reporting, particularly lack of training, also lead to lack of recognition of symptoms of abuse and consequent lack of treatment provision.

While ARC, NAPSAC, the Family Planning Association, Respond and Voice UK have become powerful advocates for the rights of the disabled to receive proper sexual education and access to treatment, the specialist treatment required is rare.

However, in addition to long-term treatments, abuse victims can also be helped by a range of complementary shorter-term treatments or combinations of treatments. For example, behaviour therapy and psychoanalytic psychotherapy can make an important combination (Sinason, 1993a) for people who harm themselves or are violent to others. This group of people have been so deprived that the combination of different therapies can be perceived as making up for environmental deficits rather than being counter-productive.

Individual and group psychoanalytic psychotherapy within the National Health Service for children and adults with learning disabilities who were emotionally disturbed or hurt by abuse and other trauma was pioneered by the Yorkshire Association for Psychodynamic Psychologists, by St Georges Hospital Medical School Psychiatry of Disability Department and by the Tavistock Clinic in London in the 1980s. As such treatment depends on 'emotional' rather than cognitive intelligence (Stokes \& Sinason, 1992) the severely and profoundly learning-disabled are able to benefit and show a reduction in symptoms (Sinason, 1993a). Indeed, there is no level of disability which makes someone ineligible for psychoanalytic treatment (Hollins et al, 1994). The only difference is the technique used with people with little or no verbal or sign language. In these circumstances adults are provided with drawing equipment, anatomical dolls and other items so that concerns can be communicated by non-verbal means. Sinason (1993a) found large home-shopping catalogues 
particularly useful. More recent additions to a 'psychotherapy kit' for adults with limited language abilities are the adult picture books on male and female abuse (Hollins et al, 1993a,b) produced by St George's Hospital Medical School in the 'Books Beyond Words' series.

The stages and themes that have to be explored and worked through with learning-disabled abuse victims share similarities with other victims. There is often a sense of betrayal of trust, shame, selfdisgust, fear of telling a secret, guilt at sexual excitement or involuntary responses. Where the abuse was not perpetrated by a stranger but by a trusted worker, family member or friend, there are the issues of poor family attachment, low self-esteem and little or poor sex education (Brown \& Craft, 1992) prior to the abuse.

However, there are areas that can be more damaging for people with learning disablities that need to be worked through in non-directive therapy. While the non-disabled child or adult can be fearful of a violent response from the abuser on telling the secret, the disabled child or adult is even more frightened because of the knowledge that some people really do wish they were dead because of their disability.

\section{Case example - Ms A.}

Ms A., after speaking of the physical and sexual violence she experienced from her care worker, whispered "If I get a baby from all that, will it be thick like me? Will I have to kill it, you know, like you can when it is a baby like that".

It is hard for disabled abuse victims to differentiate societal wishes to stop someone like them from being born and actually killing them after they are born, especially when they are being sadistically abused.

The fantasy that disability is caused by a damaging parental intercourse (Sinason, 1993a) means that abuse victims have to bear, on top of the trauma of the abuse, the reawakening of primitive fears and fantasies about their disability.

The lack of cognitive functioning can mean that painful aspects of the abuse cannot be mentally processed and symbolised. Out of 140 people referred as a result of sexual abuse (Sinason, 1993b) the most significant referral symptom was selfinjury. In some cases this is identification with the aggressor, attacking one's own body as the hated helpless victim that was not strong enough to withstand the attack. In other cases there can be an attack on the body for having an involuntary orgasm' (Sinason, 1995).

\section{Case example - Ms B.}

Ms B. was referred for cutting her vagina with different implements. "Stupid!", she shouted, "It liked it, I'll kill it". When the therapist commented "It wanted to help you, to stop you being killed", Ms B. was able to cry and talk of how frightened she had been.

Group psychotherapy for victims is also a valuable treatment. Sharing the shame, fear, excitement and powerlessness can promote change. Most authors consider that co-therapists are more suitable than single therapists because of the degree of disturbance involved (Piggot, 1987), the need to contain grief and anger (McCormack, 1991) and the freedom to hate one therapist without feeling the whole world has been destroyed (McCormack \& Sinason, 1996).

Cognitive therapies can be adapted for use in people with learning disability and may be particularly useful when the diagnosis of PTSD has been made. Dolan (1991) describes how "safe remembering" and re-structuring of the abusive memory can empower the victim to overcome their feelings of helplessness and guilt. A combination of verbal and visual techniques, for example art, may enable cognitive techniques to be used in people with poor verbal skills. Music therapy allows the expression of inner feelings that are not dependent on verbal communication (Heal, 1989) while the unconscious imagery of art (Buckley, 1989) allows primitive fears and fantasies to be worked through. Where there is verbal ability, drama therapy can be a valuable treatment too.

Physical treatments may occasionally be necessary if there is severe psychiatric illness present as a result of the abuse (Bernal \& Hollins, 1995; see Box 4). In particular, use of antidepressants can be extremely valuable in cases of

Box 4. Treatment issues for victims with learning disability

Psychiatric illness precipitated by abuse in a person with learning disability should be treated in the same way as it would be in the general population

Psychotherapeutic approaches used for victims of abuse are currently being adapted and developed for use with people with all degrees of learning disability

It may be necessary and desirable to use several different therapeutic approaches simultaneously, e.g. an antidepressant + art therapy + self-assertiveness training

Defects in cognitive functioning and limited maturation may make it impossible to process the memories and emotions induced by the abuse, leading to chronic psychological dysfunctioning 
severe depression, perhaps accompanied by anxiety, by enabling the mood to be lifted sufficiently for other therapeutic work to be effective. L. B. C. has found that treatment may need to be continued for a considerable period (at least a year) in order to be effective. For example, a young woman with Down's syndrome who suffered severe sexual abuse six years ago with resulting PTSD is responding to a combination of fluoxetine, art therapy, horse-riding and milieu therapy. Major tranquillisers are rarely of value and should only be used if there is definite psychotic illness present.

Dealing with severe self-injury following abuse has led to creative attempts to explore the benefits of other treatments. Aromatherapy, hydrotherapy, massage, horse-riding, the Snoezelen and other sensory-motor treatments can be of use with those with severely self-destructive behaviour. L. B. C. uses beauty treatments for female abuse victims in order to help them rediscover the value of their own femininity and to help them feel happy with their bodies once more.

\section{Treatment of perpetrators}

Until recently, the extent of abuse in the people with learning disabilies was kept even more secret than the extent of abuse in general. This group has been the burdened recipient of societal fantasies and fears about sexuality to the extent that some workers have been unwilling to pay adequate attention to this problem. It is commonly agreed (Sinason, 1993b) that deviant sexual behaviour is similar for disabled and non-disabled offenders, but that the offender with a learning disability is less likely to reach the courts and, therefore, receive treatment. However, such offenders can be more violent (Gilby et al, 1989) and are more likely to find male victims. Eileen Vizard's pioneering Young Abuser Project has found learning-disabled offenders are over-represented.

Recidivism in learning-disabled sex offenders is common (Day, 1993). In Day's study 85\% of sex offenders had committed more than one type of sex offence, $20 \%$ had committed both homosexual and heterosexual offences and $50 \%$ had committed offences against both children and adults. Day (1993) also found that learning-disabled sex offenders have suffered adverse psychosocial factors including parental violence, sexual abuse and multiple family pathology. He differentiates between sex offenders who commit sexual offences only and a smaller group whose sex offending is part of a larger context of offending behaviour.
Box 5. Treatment issues for perperators with learning disability

Many perpetrators may have been victims of abuse themselves

They may not receive treatment because they are not identified by the criminal justice system

Recidivism is common

Those who commit sexual offences only may be more amenable to treatment than those who have a range of offending behaviours

There has been little research to date on outcomes of psychotherapeutic treatment

He considers the former group within the learning disability population more amenable to both treatment and educational packages(see Box 5).

Psychoanalytic psychotherapy, whether as an individual or group treatment, has been a scarce resource with all offenders, let alone those with learning disabilities (Glasser, 1988, 1996; Rosen, 1979). Glasser (1988) has commented on a quality of 'dullness' in some paedophiles, which is not a manifestation of low organic intelligence but an aspect of the experience of abuse. He speculates on whether this process could be a component of the interaction between the paedophile and the victim. Indeed, as one of the significant consequences of abuse can be a process of 'stupefaction' (Sinason, 1988 ) in non-disabled children and adults, it is important to note that such trauma in those who are already disabled can lead to even further gaps in cognitive functioning.

Sinason \& Hollins are currently evaluating the impact of therapy on a group of learning-disabled sex offenders. Where therapy is not taking place on-site but on an out-patient basis, care needs to be taken over transport, reliability of escorts and safety of premises.

Cognitive-behavioural therapy and behavioural management techniques aiming to decrease deviant arousal can be effective in L. B. C.'s experience.

The same range of creative and milieu therapies that can be provided for victims are applicable to offenders. Indeed, the division made between victims and offenders can in some cases be a false one, particularly in those with learning disabilities. Many perpetrators have been victims of sexual, emotional or physical abuse. Although Browne (1993) has found that only one abuse victim in 14 goes on to become a perpetrator, thus 13 out of 14 victims do not repeat the cycle, the one in 14 who does repeat the experience is responsible for the greatest amount of sexual crimes. 
Sometimes it may be necessary to use antiandrogens such as cyproterone acetate in order to reduce plasma testosterone levels and consequently reduce the sexual drive. These can be used for short periods while other therapeutic techniques are being instigated. However, a few people will need to take these on a more long-term basis. A second opinion does not need to be obtained under the Mental Health Act 1983 for these treatments, but the individual should be made aware of the possible side-effects of this type of medication. If there is any doubt about the person being able to give valid consent to this medication, it would be good practice to gain a second opinion.

\section{Training and prevention}

Raising awareness of abuse among professional staff is the most important single measure towards prevention. Indeed, the more staff that are trained the higher the level of abuse disclosures and consequent treatment (Sinason, 1993b). While treatment provision is still uneven, there is a body of preventive educational and training packages for national (although nonstatutory) use (ARC \& NAPSAC, 1993).

Advocacy programmes, pioneered at centres like the City Literacy Institute, by Jon Hersov or by learning-disabled people such as People First have had a powerful effect.

Sex education courses (Kempton, 1988; McCarthy \& Thompson, 1992) can be used to increase levels of basic knowledge on sexual matters (Hames \& Hyde, 1995), and social skills groups are often very valuable in terms of using peer groups to increase assertiveness and self-confidence.

\section{Conclusion}

When we remember that abuse in the general population was only considered seriously by professionals in the past decade in the UK, we can be proud that the field of learning disability has taken on the subject of abuse so promptly, thoroughly and in a multi-disciplinary way (Cooke, 1995). When an individual is not capable of managing their life totally on their own and requires a team of professionals, that team needs to learn how to work together cooperatively in the best interests of its subjects.

It may be the case that, out of the nightmare that is the abuse of vulnerable people, will come long-term benefits such as the development of new therapeutic techniques and major advances in multi-agency working.

\section{References}

Association for Residential Care \& National Association for the Protection from Sexual Abuse of Adults and Children with Learning Disabilities (1993) It Could Never Happen Here! The Prevention and Treatment of Sexual Abuse of Adults with Learning Disabilities in Residential Settings. London: ARC \& NAPSAC.

Bernal, J. \& Hollins, S. (1995) Psychiatric illness and learning disability: a dual diagnosis. Advances in Psychiatric Treatment, 1, 138-145.

Brown, H. \& Craft, A. (1992) Working with the 'Unthinkable' Manual on the Sexual Abuse of Adults with Learning Difficulties. London: Family Planning Association.

Browne, K. (1993) Violence in the family and its links with child abuse. In Clinical Paediatrics, Child Abuse (eds C. J. Hobbs \& J. M. Wynne), pp. 149-165. London: Baillière Tindall.

Buckley, A. (1989) Unconscious imagery. In Mutual Respect (ed. D. Brandon), pp. 75-89. Minehead: Good Impressions Publishing.

Cooke, L. B. (1989) Abuse of mentally handicapped adults. British Medical Journal, 299, 392.

- (1990) Abuse of mentally handicapped adults. Psychiatric Bulletin, 14, 608-609.

- (1995) Dealing with the unthinkable: the abuse of people with mental handicap. Italian Journal of Intellective Impairment, 8, 23-29.

Day, K. (1993) Crime and mental retardation: a review. In Clinical Approaches to the Mentally Disordered Offender (eds K. Howells \& C. R. Hollin). Chichester: John Wiley and Sons.

Dolan, Y. M. (1991) Resolving Sexual Abuse. London: W.W. Norton.

Gilby, R., Wolf, L., Goldberg, B., et al (1989) Mentally retarded adolescent sex offenders. A survey and pilot study. Canadian Journal of Psychiatry, 34, 542-548.

Glasser, M. (1988) Psychodynamic aspects of paedophilia. Psychoanalytic Psychotherapy, 3, 121-135.

- (1996) Some aspects of the role of aggression in the perversions. In Sexual Deviations (ed. I. Rosen)(3rd edn), pp. 279-299. Oxford: Oxford University Press.

Hames, A. \& Hyde, S. (1995) Teaching self-protection skills to sexual abuse victims who have severe and profound disabilities. NAPSAC Bulletin, September, 12-16.

Heal, M. (1989) In tune with the mind. In Mutual Respect (ed D. Brandon), pp. 45-57. Minehead: Good Impressions Publishing.

Hollins, S., Sinason, V. \& Webb, B. (1993a) Jenny Speaks Out. London: St Georges Hospital Medical School Psychiatry of Disability Department.

-, - \& Webb, B. (1993b) Bob Tells All. London: St Georges Hospital Medical School Psychiatry of Disability Department.

- - \& Thompson, S. (1994) Individual, group and family psychotherapy. In Mental Health in Mental Retardation, Recent Advances and Practices (ed. N. Bouras), pp. 233-244. Cambridge: Cambridge University Press.

Kempton, W. (1988) Life Horizons I \& II. Sex Education for Persons with Special Needs. Santa Monica, CA: James Stanfield.

Law Commission (1995) Mental Incapacity: Item 9 of the Fourth Programme of Law Reform: Mentally Incapacitated Adults. Report No. 231. London: HMSO.

McCarthy, M. \& Thompson, D. (1992) Sex and the Three Rs, Rights, Responsibilities and Risks: A Sex Education Package for Working with People with Learning Difficulties. Brighton: Pavilion.

McCormack, B. (1991) Thinking, discourse and the denial of history: Psychodynamic aspects of mental handicap. Irish Journal of Psychological Medicine, 8, 59-64.

- \& Sinason, V. (1996) Mentally handicapped children and adolescents. In Group Therapy with Children and Adolescents (eds P. Kymissis \& D. Halperin), pp. 225-243. Washington, DC: American Psychiatric Asssociation. 
Oliver, C., Murphy, G. H. \& Corbett, J. A. (1987) Self-injurious behaviour in people with mental handicap: A total population study. Journal of Mental Deficiency Research, 31, 147-162.

Piggot, C. (1987) Discussion on the paper by Pantlin, A.W. Group Analysis, 20, 51-53.

Rosen, I. (ed.) (1979) Sexual Deviation. Oxford: Oxford University Press.

Ryan, R. (1994) Post-traumatic stress disorder in persons with developmental Disabilities. Community Mental Health Journal, 30, 45-54.

Royal College of Psychiatrists (1996) College Policy Statement on Rape, Council Report CR47. London: Royal College of Psychiatrists.

Sinason, V. (1986) Secondary mental handicap-its relationship to trauma. Psychoanalytic Psychotherapy, 2, 131-154.

- (1988) Smiling, swallowing, sickening, stupefying: the effect of abuse on the child. Psychoanalytic Psychotherapy, 3, 97-111.

- (1993a) Mental Handicap and the Human Condition. London: Free Association Books.

- (1993b) The vulnerability of the handicapped child and adult. In Clinical Paediatrics, Child Abuse (eds C. J. Hobbs \& J. M. Wynne), pp. 69-87. London: Baillière Tindall.

- (1995) From Abused to Abuser in Forensic Psychotherapy, Crime, Psychodynamics and the Offender Patient. Mainly Theory 2 (eds C. Cordess \& M. Cox), pp. 371-383. London: Jessica Kingsley.

Sobsey, D. \& Varnhagen, C. (1989) Sexual Abuse and Exploitation of People with Disabilities: Towards Prevention and Treatment. Vancouver: Centre for Human Development and Research.

Stokes, J. \& Sinason, V. (1992) Secondary mental handicap as a defence. In Psychotherapy and Mental Handicap (eds A. Waitman \& S. Conboy-Hill), pp. 46-59. London: Sage.

Turk, V. \& Brown, H. (1993) The sexual abuse of adults with learning disabilities: results of a two-year incidence survey. Mental Handicap Research, 6, 193-216.

\section{Multiple choice questions}

1. Sexual abuse of people with learning disabilities:

a is extremely rare

b most victims are female

c all perpetrators are male

d most perpetrators are strangers

e most perpetrators abuse more than one victim.

2. Presentations of sexual abuse in people with learning disabilities commonly include:

a sexually inappropriate behaviour

b victim reporting abuse to the police

c decrease in self-injurious behaviour

d sleep disturbance

e withdrawal.
3. Treatment for people with learning disabilities who have been sexually abused includes:

a individual psychoanalytic psychotherapy

b music therapy

c group psychoanalytic psychotherapy

d routine use of major tranquillisers

e antidepressants, especially selective serotonin reuptake inhibitorss.

4. Legal issues relating to sexual abuse of members of the population with learning disabilities:

a organisations should develop abuse procedures along the lines of child protection procedures

b special training for care staff is rarely necessary

c the Mental Health Act 1983 already covers all issues related to the care, protection and safe placement of victims

d prosecutions against offenders are usually successful

e most cases of sexual abuse will result in the trial of the alleged offender.

5. For learning disabled sexual offenders:

a recidivism is rare

b family pathology is common

c they tend to use less violence in their assaults than offenders without learning disabilities

d they are more likely to find female victims

e they are less likely to reach court and treatment than offenders without learning disabilities.

\begin{tabular}{|lllllll|}
\hline MCQ & answers & & & & \\
1 & 2 & 3 & 4 & 5 & \\
a F & a T & a T & a T & a F \\
b T & b F & b T & b F & b T \\
c F & c F & c T & c F & c F \\
d F & d T & d F & d F & d F \\
e T & e T & e T & e F & e T \\
\hline
\end{tabular}

